\title{
Estimation the Initial Cement Dosage of Concrete from Mechanical Behavior and Chemical Analysis
}

\author{
Quoc Gia Hoang, Quoc Vuong Vu* \\ Faculty of Civil Engineering, Thuyloi University, 175 Tay Son, Dong Da, Hanoi, Vietnam
}

Received May 14, 2020; Revised June 24, 2020; Accepted July 29, 2020

Copyright $\odot 2020$ by authors, all rights reserved. Authors agree that this article remains permanently open access under the terms of the Creative Commons Attribution License 4.0 International License

\begin{abstract}
The objective of this work is to determine a reliable experimental procedure and calculation method from simple laboratory tests to identify the initial cement dosage of the concrete in the hardened state and how to apply in quality inspection of a construction work. To reach the objective of the project, a combination of two methods was used: Inert method and Soluble silica method. The proposed approach is based on two series of experiments (mechanical and physical tests and chemical analysis tests), a comprehensive analysis that incorporates chemical analysis of the binder phase and lost on loss of ignition (LOI), porosity (void volume) and density of the mortar or concrete. The results of the physical and mechanical tests (the compressive strength, the porosity accessible to water, the density) present an overall picture on the properties of hardened concrete. These data then make it possible to calculate the cement dosage. The validation of this method will be carried out on different concretes with the same type and dosage of cement $\left(350 \mathrm{~kg} / \mathrm{m}^{3}\right)$, the values of W/C varying from 0.5 to 0.8 and two value of superplasticizer (a new generation modified polycarboxylate). The results show a very good concordance between the two methods and the calculated cement dosage (the average value of both methods) corresponds perfectly to the actual dosage.
\end{abstract}

Keywords Concrete Structure, Quality Inspection, Cement Dosage, Mix Design, W/C Ratio

\section{Introduction}

Concrete is currently the most widely used material in the construction industry, with three tons per year used for every person on earth $[1,2]$. Therefore, the quality and cost of concrete greatly affect the economic and technical properties of construction works. Both of these factors are dictated by the mix design of concrete, and the most important factor is the cement content, the water / cement ratio, the admixture content. The common way of controlling quality is the inspection of finished parts of a concrete structure. Normally, the quality inspection of the construction is proceeded to make sure that all materials and procedures comply with the plan and specifications. But for a concrete structure, it seems hard to control the mix design to meet the design requirement [3].

Concrete production process is usually designed to meet workability, target strength and durability requirement. This process is referred to the mix design, which decides the quantity and proportions of various component materials to produce the concrete. Actually, the quality inspection of concrete structure usually focuses on testing concrete strength by destructive methods (sampling drilling) or non-destructive (rebound hammer, ultrasonic pulse velocity) $[4,5]$. In fact, there are many concrete structures meeting the strength requirements but after a period of usage, the damage still appears $[6,7]$. The reason is that the concrete components do not meet the requirements of the minimum cement dosage or minimum $\mathrm{W} / \mathrm{C}$ ratio, etc., or the mix design of concrete is not suitable for the working environment. This is especially important for the anti-erosion or waterproofing structure $[8,9]$.

Among main components of concrete, hydraulic binder (cement) is always the most important constitution and the cement dosage strongly influences the strength and durability of concrete $[10,11,12]$. Hydraulic binders have the property of hardening on addition of water, and after hardening they still retain their strength and stability even under water. The most used hydraulic binders in construction are Portland cements. Common constituents are clinker, to which it can be added according to their types: limestone, blast furnace slag, fly ash, fine limestone, natural pozzolan, calcined schist, silica fume.

When the concrete is damaged (cracking, lack of resistance, etc.,) the quality of the used concrete is often questioned, particularly the respect of the Water/Binder ratio related to the standard EN 206-1 [13]. However, the obtained results are often surprising and criticized. 
Therefore, this work proposes a rational method in order to estimate the initial cement dosage of a hardened concrete from chemical analysis of the binder phase and mechanical experiment that include compressive strength, bound water content measurements, porosity (void volume) and density of the mortar or concrete. These data then make it possible to calculate the cement dosages under certain hypotheses (occluded air, etc ...) and this result can be applied in the field of quality inspection of construction.

\section{Methodologies}

We use 2 methods to determine the cement dosage: soluble silica method and inert method. There are currently no standards relating to the determination of cement dosage in hardened concrete. So 2 methods used in this study were developed from the procedure recommended by GranDuBé [14]

\subsection{Soluble Silica Method}

This method allows to calculate the percentage of cement in the concrete by a simple ratio between the silica solubilized in a concrete by an attack with dilute nitric acid and the silica content measured in the corresponding cement. In the case where the cement is not identified (most frequent case), the soluble silica content of the cement will be estimated by taking an average value depending on the type of cement.

The soluble silica content is determined by gravimetric method (with quinoline) or by plasma emission spectrometry (ICP-AES) or by atomic absorption (SAA).

The cement content $C_{1}$ is expressed according to the following relation:

$$
\boldsymbol{C}_{1} \%=\frac{\mathrm{SiO}_{2} \text { sol }^{B_{0}}}{\mathrm{SiO}_{2} \text { sol }_{\%}} \times 100
$$

The indices $\mathrm{B}$ and $\mathrm{C}$ relate respectively to concrete (or mortar) and cement.

Taking into account the soluble silica content of the cement:

1st possibility: $\mathrm{SiO}_{2}{ }^{\text {solC }} \%$ is known or can be determined experimentally according to the operating procedures or we have a sample of cement used in the composition of the concrete or mortar;

\begin{tabular}{|c|c|c|c|c|c|}
\hline Cement & CEM I & $\begin{array}{c}\text { CEM } \\
\text { II/A }\end{array}$ & $\begin{array}{c}\text { CEM } \\
\text { III/A }\end{array}$ & $\begin{array}{c}\text { CEM } \\
\text { III/B }\end{array}$ & $\begin{array}{c}\text { CEM } \\
\text { III/C }\end{array}$ \\
\hline $\mathrm{SiO}_{2}{ }^{{ }^{\circ o l C}} \%$ & $20,5 \pm 2$ & $23 \pm 1,5$ & $26 \pm 3$ & $27,5 \pm 1.5$ & $31 \pm 1.5$ \\
\hline
\end{tabular}

2nd possibility: In the opposite case, $\mathrm{SiO}_{2}{ }^{{ }^{\mathrm{solC}}} \%$ is chosen in the table below according to the cement category 1.

\subsection{Inert Method}

The cement content is considered to be a difference of 100 and the combined and bound volume of water.

$$
\mathrm{C}_{2} \%=100 \% \text { - [aggregate }+ \text { bound water] }
$$

The siliceous and calcareous aggregates as well as the bound water are globally determined by the sum of the insoluble fraction, the loss on ignition and the $\mathrm{CaO}$ content related to carbon dioxide.

The cement content is, conventionally, the difference to 100 of this sum.

$$
\mathrm{C}_{2} \%=100-[\text { insoluble }+ \text { loss on ignition }]
$$

The insoluble fraction corresponds to siliceous aggregates. It is determined by a method of attack of the concrete by dilute nitric acid.

The loss on ignition is determined according to standard EN 146-2 or by thermogravimetry. It corresponds to the bound water content of the concrete, the content of organic matter that may be present and the $\mathrm{CO} 2$ of the carbonates (calcareous aggregates and carbonate part of the cement).

\subsection{Calculation the Most Probable of Cement Content}

The calculation of the cement content is as follow:

$$
\mathrm{C} \%=\left(\mathrm{C}_{1}+\mathrm{C}_{2}\right) / 2
$$

The difference between the results obtained by two methods must be less than $10 \%$ of the average value. In this case, the percentage of cement is taken equal to the average of the values $C_{1}$ and $C_{2}$.

Determination of Cement Dosage $\left(\mathrm{Kg} / \mathrm{M}^{3}\right)$

The cement dosage $\mathrm{D}\left(\mathrm{kg} / \mathrm{m}^{3}\right)$ is calculated from the following formula:

$$
D=\frac{C \times \rho_{d} \times 1000}{100}
$$

with:

$\mathrm{C}$ : cement content based on the weight of concrete $(\%)$; $\mathrm{d}$ : apparent density

\section{Materials and Experimental Procedure}

All concretes of the study are prepared with a Portland cement CEM I 52.5R, according to the European Standard EN 197.1 [15] and the French standard NF P 15318 [16]. Table 1 presents the main chemical and physical properties of the cement. 
Table 1. Chemical and physical properties of cement.

\begin{tabular}{|c|c|c|}
\hline Composition & Value & Unit \\
\hline $\mathrm{SiO}_{2}$ & 20.8 & $\%$ \\
\hline $\mathrm{Al}_{2} \mathrm{O}_{3}$ & 4.6 & $\%$ \\
\hline $\mathrm{Fe}_{2} \mathrm{O}_{3}$ & 2.4 & $\%$ \\
\hline $\mathrm{CaO}$ & 65.1 & $\%$ \\
\hline $\mathrm{MgO}$ & 2.0 & $\%$ \\
\hline $\mathrm{SO}_{3}$ & 3.4 & $\%$ \\
\hline $\mathrm{K}_{2} \mathrm{O}$ & 0.86 & $\%$ \\
\hline $\mathrm{Na}_{2} \mathrm{O}$ & 0.11 & $\%$ \\
\hline $\mathrm{Cl}-$ & 0.06 & $\%$ \\
\hline $\mathrm{Na}_{2} \mathrm{O}$ equivalent & 0.67 & $\%$ \\
\hline mhysical and mechanical properties & & \\
\hline 2 days compressive strength & 30 & $\mathrm{MPa}$ \\
\hline 2 days compressive strength & 41 & $\mathrm{MPa}$ \\
\hline 28 days compressive strength & 63 & $\mathrm{MPa}$ \\
\hline Blaine specific surface area & 5200 & $\mathrm{~cm} / \mathrm{g}$ \\
\hline Density & 3.14 & $\mathrm{~g} / \mathrm{cm}^{3}$ \\
\hline Water demand for standard paste & 31 & $\%$ \\
\hline Final setting time & 2.45 & $\mathrm{hh} . \mathrm{mm}$ \\
\hline
\end{tabular}

A new generation modified polycarboxylate VMAT PC $\mathbf{0 1}$ is used as superplasticizer allowing efficient dispersion of cement particles and improving grout's flowability for extending duration. Table 2 presents the main properties of this superplasticizer.

Table 2. Main properties of superplasticizer VMAT PC 01

\begin{tabular}{|c|c|c|}
\hline Properties & Value & Unit \\
\hline Density & $1.08 \pm 0.02$ & $\mathrm{~g} / \mathrm{cm}^{3}$ \\
\hline $\mathrm{pH}$ & $6 . \pm 2$ & \\
\hline $\mathrm{Cl}^{-}$ & $<0.1$ & $\%$ \\
\hline $\mathrm{Na}_{2} \mathrm{O}$ equivalent & $<2$ & $\%$ \\
\hline Dry material content & $20 \pm 1.5$ & $\%$ \\
\hline $\begin{array}{c}\text { Recommended dosage } \\
\text { (/cement) }\end{array}$ & $0.2-2$ & $\%$ \\
\hline
\end{tabular}

The study is carried out with six mix design of concretes whose W/C ration vary from 0.5 to 0.8 . The dosage of cement is $350 \mathrm{~kg}$ of $1 \mathrm{~m}^{3}$ of concrete. The mix design of the reference concrete (W/C 0.5$)$ is showed in table 3

Table 3. The mix design of concrete with $\mathrm{W} / \mathrm{C}$ ratio 0.5

\begin{tabular}{|c|c|c|}
\hline \multicolumn{2}{|c|}{ Composition } & Quantity $(\mathrm{kg} / \mathrm{m} 3)$ \\
\hline \multirow{4}{*}{ Aggregate } & $\mathbf{0 / 0 . 3 1 5}$ & 234.0 \\
\cline { 2 - 3 } & $\mathbf{0 . 3 1 5} / \mathbf{1}$ & 59.2 \\
\cline { 2 - 3 } & $\mathbf{1 / 4}$ & 376.0 \\
\cline { 2 - 3 } & $\mathbf{4 / 8}$ & 68.0 \\
\cline { 2 - 3 } & $\mathbf{8 / 1 2 . 5}$ & 68.0 \\
\cline { 2 - 4 } & $\mathbf{1 2 . 5 / 2 0}$ & 941.2 \\
\hline \multicolumn{2}{|c|}{} & 350.0 \\
\hline \multicolumn{2}{|c|}{ Cement } & 175.0 \\
\hline \multicolumn{2}{|c|}{ Water } & \\
\hline
\end{tabular}

The experimental procedures are carried out as follows:

- Mechanical experiment (compressive strength, porosity)

- Determination of the insoluble fraction (Fig. 1)

- Determination of soluble silica

- Determination of loss on ignition (Fig. 2)

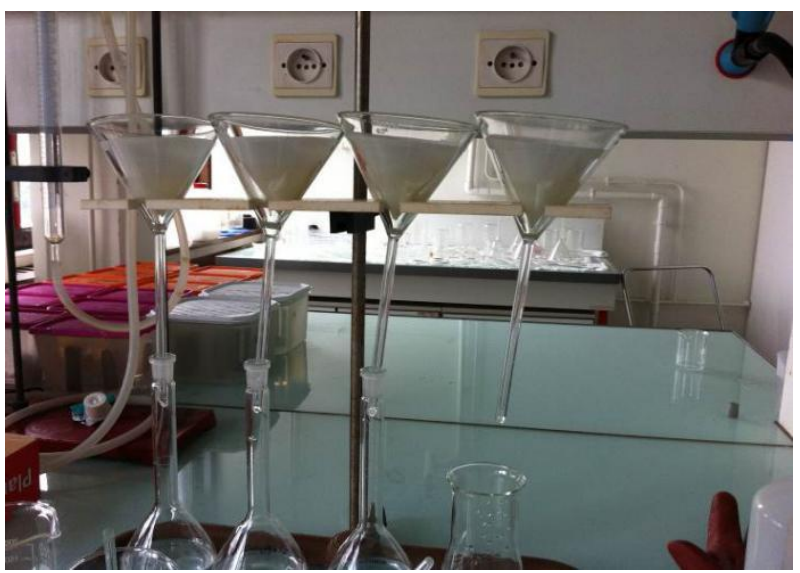

Figure 1. Method of attack of the concrete by dilute nitric acid

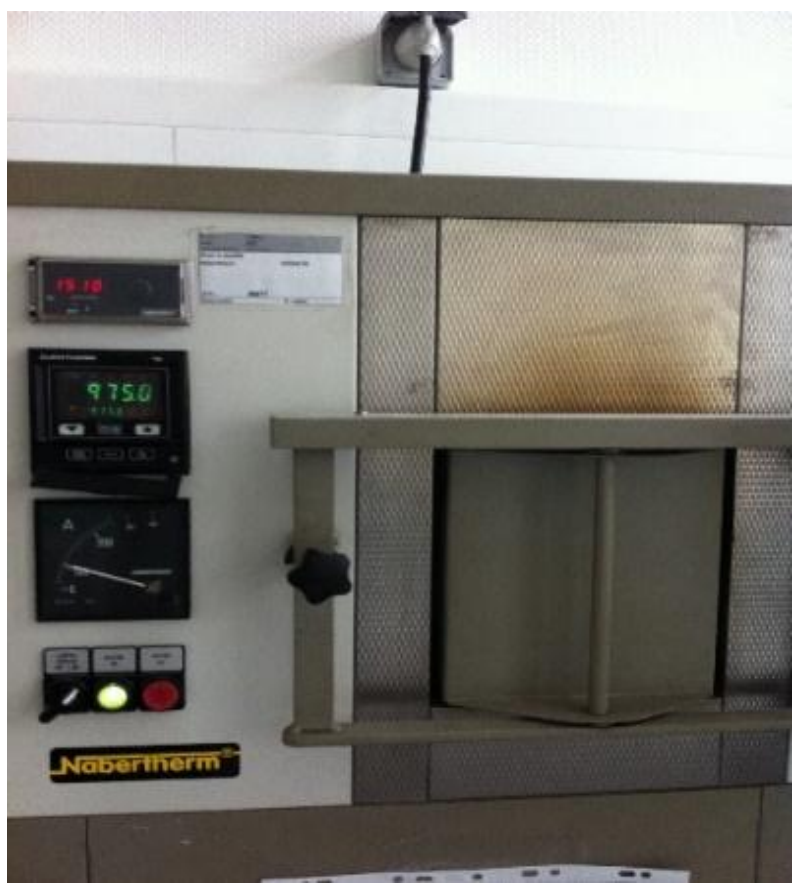

Figure 2. Calcination at $975^{\circ} \mathrm{C}$

\section{Experimental Results}

\subsection{Mechanical Behavior}

The compressive strength of concrete is generally considered to be its most important property. In fact, the compressive strength generally projects an overall picture of the quality of a concrete since it is directly related to the structure of the hydrated cement. However, the choice of 
the constitution of a concrete must not only satisfy the resistance requirements, but also guarantee a suitable durability. The mix design of concrete has a direct influence on its sustainability indicators: porosity, water, air and vapor permeability, carbonation, etc.

The porosity was determinated by hydrostatic weighing method. The principle is as follows:

- determination by weighing the apparent mass of concrete after immersion in a liquid with which it has been impregnated under vacuum

- determination of its mass in the open air while it is still soaked with liquid then dry mass

Table 4 presents the results of the compressive strength, water-porosity tests.

Table 4. Test results of mechanical properties

\begin{tabular}{|c|c|c|}
\hline Concrete & $\begin{array}{c}\text { Compressive strength } \\
(\mathbf{M P a})\end{array}$ & Porosity (\%) \\
\hline $\mathrm{E} 1(\mathrm{~W} / \mathrm{C}=0,5)$ & 50,7 & 12,1 \\
\hline $\mathrm{E} 2(\mathrm{~W} / \mathrm{C}=0,6)$ & 41,8 & 13,2 \\
\hline $\mathrm{E} 3(\mathrm{~W} / \mathrm{C}=0,7)$ & 34,6 & 14,5 \\
\hline $\mathrm{E} 4(\mathrm{~W} / \mathrm{C}=0,8)$ & 28,7 & 16,2 \\
\hline $\begin{array}{c}\mathrm{E} 5(\mathrm{~W} / \mathrm{C}=0,5 ; 1 \% \\
\text { VMAT PC 01) }\end{array}$ & 40,2 & 11,4 \\
\hline $\begin{array}{c}\text { E6 (W/C }=0,5 ; 2 \% \\
\text { VMAT PC 01) }\end{array}$ & 50,3 & 10,7 \\
\hline
\end{tabular}

The results show that the strength increases at the same time as the dosage in cement $\mathrm{C}$ and it decreases according to the dosage in water $\mathrm{W}$ and this is why we tend to take into account the $\mathrm{W} / \mathrm{C}$ ratio as a global factor intervening in the strength of concrete.

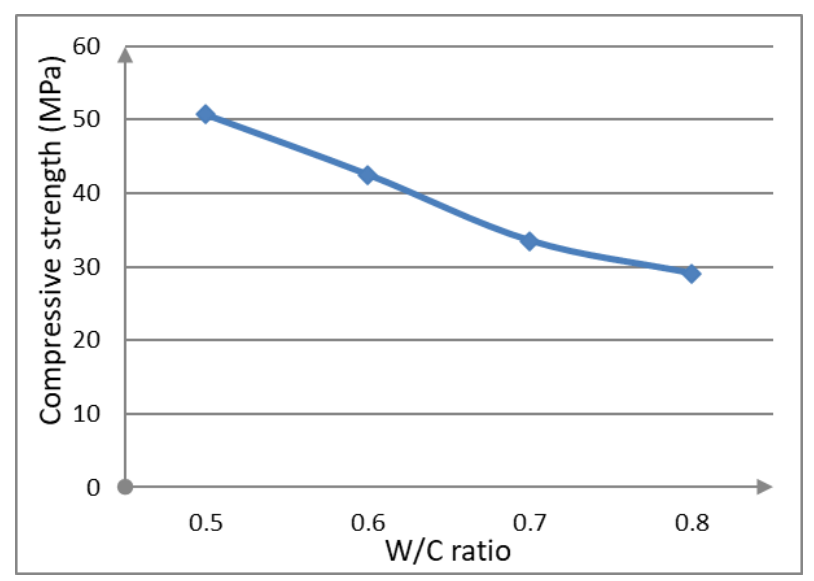

Figure 3. Variation in compressive strength as a function of the W/C ratio

We check that the water/cement ratio exerts an important influence on the compressive strength (Fig. 3) and on the porosity of hardened concrete. For the other two concretes which contain superplasticizer at dosages of $1 \%$ and $2 \%$, with the same $\mathrm{W} / \mathrm{C}$ ratio $=0.5$, the values of compressive strength are very different. It is the segregation of the concrete in the step of manufacturing the test sample which causes this phenomenon. Based on the relationship between the $\mathrm{W} / \mathrm{C}$ ratio of concrete and these two properties, and from the results of mechanical tests, we are able to estimate the $\mathrm{W} / \mathrm{C}$ ratio of concrete, especially for concretes that do not contain admixture.

\subsection{Chemical Analysis}

The formula (2) was used to estimate the cement content of concrete by inert method. The insoluble fraction of the cement is determined by the attack by nitric acid and the loss of on ignition is determined by muffling furnace calcination at $975^{\circ} \mathrm{C}$. The results of INS, LOI, cement content and quantity of cement are given in the table 5 .

The cement dosage was determined by taking the density measurable. The cement dosage is varied $350 \pm 13 \mathrm{~kg} / \mathrm{m} 3$ for this method. Therefore, the measured dosage corresponds well to the actual dosage $(350 \mathrm{~kg})$ and the dispersion of the results between the concretes is extremely low. For concretes containing admixture, the cement dosage varies from $351 \mathrm{~kg}$ to $362 \mathrm{~kg}$ by the inert method.

For the soluble silica method, the soluble silica content is determined by plasma emission spectrometry (ICP - AES). The results are presented as percentage of oxide, $\mathrm{SiO}_{2} \mathrm{Sol}^{\mathrm{B}} \%$, based on the weight of the concrete. To calculate the cement content by the soluble silica method, a cement sample is used (CEM I) and its soluble silica content of the cement is also determined. The results of the soluble silica tests are shown in table 6 .

Table 5. Test results by the inert method

\begin{tabular}{|c|c|c|c|c|}
\hline Concrete & $\begin{array}{c}\text { INS } \\
(\%)\end{array}$ & $\begin{array}{c}\text { LOI } \\
(\%)\end{array}$ & $\begin{array}{c}\text { Cement } \\
\text { content } \mathrm{C}_{2} \\
(\%)\end{array}$ & $\begin{array}{c}\text { Quantity } \\
\text { of Cement } \\
(\mathrm{kg})\end{array}$ \\
\hline $\mathrm{E} 1(\mathrm{~W} / \mathrm{C}=0,5)$ & 80,44 & 4,02 & 15,54 & 353 \\
\hline $\mathrm{E} 2(\mathrm{~W} / \mathrm{C}=0,6)$ & 80,09 & 4,82 & 15,10 & 341 \\
\hline $\mathrm{E} 3(\mathrm{~W} / \mathrm{C}=0,7)$ & 79,42 & 5,75 & 14,83 & 333 \\
\hline $\mathrm{E} 4(\mathrm{~W} / \mathrm{C}=0,8)$ & 79,69 & 4,99 & 15,32 & 337 \\
\hline $\begin{array}{c}\mathrm{E} 5(\mathrm{~W} / \mathrm{C}=0,5 ; \\
1 \% \text { VMAT PC 01) }\end{array}$ & 80,48 & 4,54 & 14,99 & 351 \\
\hline $\begin{array}{c}\mathrm{E} 6(\mathrm{~W} / \mathrm{C}=0,5 ; \\
2 \% \text { VMAT PC 01) }\end{array}$ & 79,79 & 4,84 & 15,37 & 362 \\
\hline
\end{tabular}

Table 6. Test results by the soluble silica method

\begin{tabular}{|c|c|c|c|}
\hline Concrete & $\begin{array}{c}\text { Percent of } \\
\mathrm{SiO}_{2}(\%)\end{array}$ & $\begin{array}{c}\text { Cement } \\
\text { content } \mathrm{C}_{1}(\%)\end{array}$ & $\begin{array}{c}\text { Quantity of } \\
\text { Cement (kg) }\end{array}$ \\
\hline $\mathrm{E} 1(\mathrm{E} / \mathrm{C}=0,5)$ & 1,46 & 15,21 & 345 \\
\hline $\mathrm{E} 2(\mathrm{E} / \mathrm{C}=0,6)$ & 1,53 & 15,89 & 359 \\
\hline $\mathrm{E} 3(\mathrm{E} / \mathrm{C}=0,7)$ & 1,49 & 15,52 & 349 \\
\hline $\mathrm{E} 4(\mathrm{E} / \mathrm{C}=0,8)$ & 1,54 & 16,08 & 354 \\
\hline $\begin{array}{c}\mathrm{E} 5(\mathrm{~W} / \mathrm{C}=0,5 ; \\
1 \% \text { VMAT PC 01) }\end{array}$ & 1,45 & 15,14 & 354 \\
\hline $\begin{array}{c}\mathrm{E} 6(\mathrm{~W} / \mathrm{C}=0,5 ; \\
\text { 2\% VMAT PC 01) }\end{array}$ & 1,44 & 15,03 & 354 \\
\hline
\end{tabular}


Table 7. Determination of the most probable cement dosage

\begin{tabular}{|c|c|c|c|c|c|}
\hline Concrete & $\begin{array}{c}\text { Cement content } \mathrm{C}_{1} \\
(\%)\end{array}$ & $\begin{array}{c}\text { Cement content } \mathrm{C}_{2} \\
(\%)\end{array}$ & Average C (\%) & $\begin{array}{c}\text { Standard } \\
\text { deviation }\end{array}$ & $\begin{array}{c}\text { Quantity of } \\
\text { Cement }(\mathrm{kg})\end{array}$ \\
\hline E1 (E/C = 0,5) & 15,21 & 15,54 & 15,38 & 0,33 & 349 \\
\hline E2 (E/C = 0,6) & 15,89 & 15,10 & 15,50 & 0,79 & 350 \\
\hline E3 (E/C=0,7) & 15,52 & 14,83 & 15,18 & 0,69 & 341 \\
\hline E4 (E/C=0,8) & 16,08 & 15,32 & 15,70 & 0,76 & 345 \\
\hline E5 (W/C = 0,5; 1\% VMAT PC 01) & 15,14 & 14,99 & 15,07 & 0,15 & 352 \\
\hline E6 (W/C = 0,5; 2\% VMAT PC 01) & 15,03 & 15,37 & 15,20 & 0,34 & 358 \\
\hline
\end{tabular}

The cement dosage varied $350 \pm 9 \mathrm{~kg} / \mathrm{m}^{3}$ for this method. For concretes containing admixture, the cement dosage equals $354 \mathrm{~kg}$. An important point, there is a very good concordance between the two methods (soluble silica and inert). This shows that it is possible to determine the cement dosage without necessarily knowing the nature of the cement and its soluble silica content.

With these results, it can be concluded that both methods give exact cement dosage values for the cement CEM I. However, in this case where we know the nature of the cement and its soluble silica content, we can see that the result of the soluble silica method is more accurate than that of the inert method. The results also show that admixture VMAT PC 01 (modified polycarboxylate plasticizers) have no influence on the determination of the cement dosage, whatever the method used.

For the calculation the most probable of cement dosage, we take the average value of the cement content determined by the two methods, and then we observe the difference between them (table 7). It can be seen that the difference between the results obtained by the two methods is less than $10 \%$ of the average value. So the percentage of cement is taken equal to the average of the values $\mathrm{C} 1$ and $\mathrm{C} 2$. The determined cement dosage corresponds perfectly to the actual dosage $(350 \mathrm{~kg}$ ). It varies from $341 \mathrm{~kg}$ to 358 $\mathrm{kg}$. Using both methods and averaging them gives greater reliability in determining the cement dosage.

\section{Conclusions}

To identify the initial mix design of concrete, it is necessary to carry out two series of experiments, these are mechanical tests and chemical analysis tests. From the relationship between the mix design of concrete (the W/C ratio in particular) and its mechanical properties, we can verify the results of the chemical analysis tests. In addition, mechanical test results are necessary data in the calculation of the cement dosage.

The cement dosage is determined by the soluble silica method and the inert method. There is a very good concordance between the two methods and the calculated cement dosage (the average value of both methods) corresponds perfectly to the actual dosage. This shows that it is possible to determine the cement dosage without necessarily knowing the nature of the cement. However, in the case where the nature of the cement and its soluble silica content are identified, the result of the soluble silica method is more accurate than that of the inert method. For good results, the procedure should be carefully followed and it is recommended that both methods be used and take the average. We also note that admixture based on polycarboxylates have no influence on the estimation of cement dosages.

In the absence of information on the nature of the binder and the aggregates used, the uncertainty on the evaluated cement dosage is greatly given:

- the representativeness of the sample analyzed,

- the influence of the age of the concrete on the soluble silica content,

- the pozzolanic effect when it comes to blast-furnace slag cement, fly ash, silica fumes, pozzolans, etc.,

- the alkali reaction (presence of soluble silica other than that of the binder).

In this situation, electron scanning microscopy (SEM) is a useful complementary technique for assessing the characteristics of the cement used and confirming the presence or non-existence of additions such as blast furnace slag, fly ash, silica fume, filler siliceous or limestone, etc.

Finally, this work made it possible to significantly advance the estimation of the initial mix design of fresh concrete from the analysis of hardened concrete. The problem is to carry out further research on different types of cement, adjuvant with different dosages.

\section{REFERENCES}

[1] Colin R. Gagg, Cement and concrete as an engineering material: An historic appraisal and case study analysis, Engineering Failure Analysis, Volume 40, 2014, Pages $114-140$

[2] Hendrik van Oss G. Prepared for the US geological survey. Mineral commodity summaries; 2007.

[3] Isabel Miñano Belmonte, Francisco Javier Benito Saorin, 
Carlos Parra Costa, Manuel Valcuende Paya, Quality of the surface finish of self-compacting concrete, Journal of Building Engineering, Volume 28, 2020

[4] ASTM C805 / C805M - 18, Standard Test Method for Rebound Number of Hardened Concrete

[5] ASTM C597 - 16, Standard Test Method for Pulse Velocity Through Concrete

[6] R. Douglas Hooton, Future directions for design, specification, testing, and construction of durable concrete structures, Cement and Concrete Research, Volume 124, 2019

[7] Huijun Qi, Tongchun Li, Xiaoqing Liu, Lanhao Zhao, Chaoning Lin, Shujie Fan, A variable parameters damage model for concrete, Engineering Fracture Mechanics, Volume 228, 2020,

[8] Wen-Liang Qiu, Fei Teng, Sheng-Shan Pan, Damage constitutive model of concrete under repeated load after seawater freeze-thaw cycles, Construction and Building Materials, Volume 236, 2020

[9] Amir Javad Moradloo, Ata Adib, Amir Pirooznia, Damage analysis of arch concrete dams subjected to underwater explosion, Applied Mathematical Modelling, Volume 75,
2019

[10] NEVILLE AM., 2012, Properties of Concrete, Prentice Hall; 5 edition.

[11] Professor Dr. Joseph Davidovits. The history of concrete and the Nabataeans. <http://nabataea.net/cement.html>.

[12] Lechtman Heather, Hobbs Linn. Roman concrete and the roman architectural revolution. In: Kingery WD, (editor) Ceramics and civilization volume 3: high technology ceramics: past, present, future. The American Ceramics Society; 1986

[13] EN 206-1 Concrete - Part 1: Specification, performance, production and conformity

[14] Arliguie G., Hornain H., 2007, GranDuBé : Grandeurs associées à la Durabilité des Bétons, Presse de l'Ecole Nationale des Ponts et Chaussées

[15] N.E.197-1, 'Cement - Part 1: composition, specifications and conformity criteria for common cements,' ed, 2001-02-01, p. 31. (n.d.).

[16] N.P15-318, 'Hydraulic binders - Cement with limited sulphides content for use in prestressed concrete,' ed, 2006-09-01 p. 6. (n.d.). 